\title{
Natural Gas Power Generation to Promote the Construction of Ecological City
}

\author{
Mengfan Xie ${ }^{1, *}$, Yanyan Zou², and Yi Zhou ${ }^{3}$ \\ ${ }^{1}$ School of Management, Tianjin University of Technology, Tianjin 300384, China \\ ${ }^{2}$ School of Management, Tianjin University of Technology, Tianjin 300384, China \\ ${ }^{3}$ School of Management, Tianjin University of Technology, Tianjin 300384, China
}

\begin{abstract}
As an unsustainable resource, it is of great significance to explore more efficient and low-carbon ways of using energy. With the fast development of China's economy, most cities are faced with the pressure of ecological environment to varying degrees. The construction of ecological city is not only the need of ecological protection and improvement of natural environment, but also the requirement of urban development. Compared with coal-fired power generation, natural gas power generation has advantages in terms of environmental pollution, energy utilization efficiency and resource occupancy, and is one of the ideal energy sources for eco-city construction. However, at present, there are constraints such as lack of subsidy policy, high fuel price, dependence on import of equipment and high cost of construction and maintenance. In the long run, the development of gas-fired power generation industry should be actively and prudently promoted from the aspects of strengthening the construction of supporting facilities and the guarantee of gas source, perfecting the mechanism of electricity price, and increasing the localization rate of key equipment, so as to achieve the goal of optimizing industrial structure, saving energy and reducing emissions, and facilitating the construction of China's ecological city.
\end{abstract}

\section{Introduction}

Building a clean, low-carbon, secure and high-efficiency energy system is an important step to promote the revolution of energy production and consumption, and is the only way for the development of China's energy industry in the future ${ }^{[1]}$. In terms of energy, eco-city advocates green, efficient and recycling utilization of resources, which requires continuous improvement of energy conversion and utilization efficiency, full and reasonable utilization of natural resources, as well as reduction of the external discharge of various pollutants and reduction of the impact on the external environment.

The "coal-based" energy structure has brought about a series of environmental problems such as air pollution and climate warming, and the adjustment of energy structure has become an important way to gradually solve China's energy and environmental questions. Natural gas is a clean and efficient low-carbon energy. Accelerating the progress of the natural gas industry is the only way for China to accelerate its efforts to make the energy system cleaner, low-carbon, safe and efficient. Gradually increasing the proportion of natural gas in energy consumption is of great significance to resolve environmental constraints, improving air quality, promoting energy conservation and emission decrease, and promoting sustainable economic and social evolution ${ }^{[2]}$.

In the past decade, China's natural gas power generation has experienced rapid development (the installed capacity reached 90.22 million $\mathrm{kW}$ by the end of 2019), playing an increasingly vital role in the process of energy structure adjustment. But compared with developed countries, China's gas-fired power generation still accounts for a relatively low share of the electricity market -- 4.5 percent of installed capacity and 3.2 percent of electricity generation in 2019. However, with the introduction of relevant national environmental protection and peak regulation subsidy policies, natural gas power generation has ushered in a more favorable development environment, played a more significant role in the field of energy supply, and played a supporting role for ecology, low-carbon city construction, energy conservation, emission reduction and environmental protection ${ }^{[3]}$.

\section{The energy problem of Eco-city construction in China}

\subsection{The nature of an Eco-city}

Eco-city is a kind of complex ecosystem in which society, economy, culture and nature are highly coordinated. It can make effective use of environmental resources and achieve sustainable development. It is a new social relation, a new approach of production and life established in accordance with the principles of ecology. Eco-city advocates reducing the unnecessary consumption of all

\footnotetext{
${ }^{*}$ Corresponding author: mengfan123@stud.tjut.edu.cn
} 
kinds of energy and resources, and striving to perfect the efficiency of energy and resources conversion and use. By improving the level of renewable and comprehensive utilization of resources, research and development of alternative energy to reduce the utilization rate of fossil fuels. Finally, various scientific and technological means are used to reduce the influence of waste heat, waste water and waste gas on the external environment.

\subsection{The energy landscape of Eco-cities}

In terms of energy utilization, eco-cities focus on improving the comprehensive utilization efficiency of resources, reducing the impact of cities on the external ecological environment, and minimizing the damage caused by human activities to the natural surroundings. In order to achieve the above goals, builders of eco-cities will work hard to study new energy sources and improve the energy structure. Encourage the conservation of resources, and develop new technologies and processes to achieve the optimal effect of energy utilization; we will tap the potential of bioenergy, wind power, solar energy, geothermal energy, hydrogen energy and else renewable energy sources to diversify the energy mix and ensure energy security. In terms of energy efficiency: encourage comprehensive utilization of energy, can complement each other, promote cold hot electricity distributed energy system, such as in the community energy, solar energy, wind energy, biogas can, even the elevator down potential energy through various techniques together, complement each other, form the internal energy network to reduce energy loss, reduce the energy demand of the outside world.

\subsection{The energy problem of Eco-city construction in China}

In the process of eco-city construction in China, energy development and utilization are mainly faced with four problems :(1) Although per capita energy consumption in China is comparative low, the total energy consumption in cities is large due to the large population and large and medium-sized cities. (2) Urban energy supply is dominated by coal consumption, which leads to the longterm existence of unreasonable energy structure and heavy pressure on environmental governance. (3) Low energy efficiency. Although energy consumption per unit GDP in China has fallen by $60 \%$ over the past $20 \mathrm{a}$, it is compared to the energy consumption of millions of dollars. It's still nine times higher than Japan. (4) The rapid growth of energy-intensive industries has led to increasing energy consumption in cities and increasing impacts on the ecological environment.

\section{Natural gas power to protect the ecological positive role}

\subsection{Reduce the environmental pollution caused by electric power production}

At present, the environmental pollution caused by energy consumption is very serious. In the process of electric power production, the traditional generation of electricity from coal has caused significant pollution to the environment, which is a very important problem at present. Natural gas is a clean and high quality primary energy with the advantages of low pollutant discharge and high utilization rate. The composition of natural gas is relatively simple, and the main component is methane. Basically, it will not produce soot and sulfur dioxide when used for power generation, and the emission of carbon dioxide in the flue gas will be vastly reduced ${ }^{[4]}$. Since natural gas contains no sulfur, sulfur dioxide emissions are essentially zero. For coal-fired units, it is still difficult to achieve even if the equipment investment is increased and the flue gas desulfurization device is installed. As for NOx emissions of pollutants, the NOx emissions of new gas turbines are about half that of coal-fired power plants on account of the application of dry low NOx combustion technology. After installing SCR denitrification unit, the NOx emission concentration of gas-fired units is obviously lower than that of the most advanced ultra-low emission coal-fired units. It can be seen that increasing the installed capacity of natural gas power generation equipment will help power generation industry to achieve emission reduction targets and reduce the increasing pressure of environmental protection.

\subsection{Improve energy efficiency}

At present, there are two main ways to utilize natural gas in the power industry. (1) Combined cycle power plants mainly have different scales of $6 \mathrm{~F}, 9 \mathrm{E}$ and $9 \mathrm{~F}$. The single capacity is usually $100,000 \mathrm{~kW}, 200,000 \mathrm{~kW}$ and 400,000 $\mathrm{kW}$, and the power generation efficiency can achieve $50 \%$ $\sim 60 \%$. (2) The natural gas distributed energy system can be divided into regional distributed and building distributed systems. The capacity of a single machine varies from tens of kilowatts to tens of thousands of kilowatts, and the overall efficiency reaches about $80 \%$. However, the efficiency of $300 \sim 1000 \mathrm{MW}$ ultrasupercritical units in coal-fired power plants is only $41.9 \%$ $\sim 47.8 \%$, while the efficiency of other small capacity units with low parameters will be even lower. Therefore, the development of natural gas power generation is an effective way to achieve the national binding goal of energy conservation.

Table 1 shows the comparison of thermal efficiency between coal-fired and gas-fired units. The first column is unit type, the second column is unit capacity, the third column is some basic parameters, and mainly including pressure ratio and gas initial temperature, and the last column is thermal efficiency. It can be seen from the table that the thermal efficiency is $42.5 \%, 45.0 \%, 47.8 \%, 56.3 \%$, $58.5 \%$, and $60.0 \%$ respectively from top to bottom. It can be seen that $\mathrm{S} 109 \mathrm{H}$ in the gas unit has the highest thermal efficiency. 
Table 1. Comparison of the combined cycle thermal efficiency between coal-fired power generation and gas-steam turbine.

\begin{tabular}{|c|c|c|c|}
\hline Type & Capacity & $\begin{array}{c}\text { Pressure ratio } \\
\text { and gas initial } \\
\text { temperature }\end{array}$ & $\begin{array}{c}\text { Thermal } \\
\text { efficiency } \\
(\%)\end{array}$ \\
\hline \multirow{3}{*}{$\begin{array}{l}\text { Coal- } \\
\text { fired } \\
\text { units }\end{array}$} & $\begin{array}{c}500 \mathrm{MW} \\
\text { supercritical } \\
\text { unit }\end{array}$ & $\begin{array}{c}25.0 \mathrm{Mpa} \\
540 / 560^{\circ} \mathrm{C}\end{array}$ & $42.5 \%$ \\
\hline & $\begin{array}{c}700 \mathrm{MW} \\
\text { supercritical } \\
\text { unit }\end{array}$ & $\begin{array}{c}31.1 \mathrm{Mpa} \\
566 / 566^{\circ} \mathrm{C}\end{array}$ & $45.0 \%$ \\
\hline & $\begin{array}{c}\text { 1000MW USC } \\
\text { turbo-generator } \\
\text { unit }\end{array}$ & $\begin{array}{c}31 \mathrm{Mpa} \\
600 / 610 / 610 \\
{ }^{\circ} \mathrm{C}\end{array}$ & $47.8 \%$ \\
\hline \multirow{3}{*}{$\begin{array}{l}\text { Gas- } \\
\text { fired unit }\end{array}$} & $\begin{array}{c}348.5 \mathrm{MW} \\
\text { S109FA }\end{array}$ & $\begin{array}{c}14.7 \mathrm{Mpa} \\
1320^{\circ} \mathrm{C}\end{array}$ & $56.3 \%$ \\
\hline & 396MW KA26 & $\begin{array}{c}30 \mathrm{Mpa} \\
1260^{\circ} \mathrm{C}\end{array}$ & $58.5 \%$ \\
\hline & 420MW S109H & $\begin{array}{c}23.2 \mathrm{Mpa} \\
1430^{\circ} \mathrm{C}\end{array}$ & $60.0 \%$ \\
\hline
\end{tabular}

\subsection{Reduce resource occupancy}

Natural gas power generation projects also use fewer resources than coal-fired power plants: (1) the plant uses less electricity. The auxiliary and auxiliary systems of gas turbine power plant are simple, and the power consumption rate is generally less than $2 \%$. (2) Less water consumption. As the combined cycle steam turbine size in natural gas power plants is generally $1 / 3$ of the total capacity, the power plant uses about $30 \%$ of the water of coal-fired power plants. (3) The power plant occupies a small area. The fuel of natural gas power plant is natural gas, and no coal and ash storage yard is needed, so the project covers an area of great savings. The area of gas power plant with unit kilowatt capacity is about $15 \% \sim 35 \%$ of that of coal power plant. (4) Shorter project construction cycle. With more modular and standardized equipment, natural gas power plants can expand their installed capacity in smaller increments, resulting in shorter infrastructure cycles and less investment. The construction period of coal-fired thermal power plant is generally 2-3a, while that of gas-steam combined cycle power plant is about 12 months, and that of peak-regulating power plant is less than 10 months.

The above data fully show that under the increasingly severe situation of energy conservation and environmental protection, natural gas power generation has made an extremely significant contribution to resource conservation and ecological environment protection.

\section{Current situation of natural gas power generation}

Since the beginning of the 21 st century, China's natural gas power generation has been gradually developing and expanding. By the end of 2019, its installed capacity has exceeded 90 million $\mathrm{kW}$. As shown in Figure 1, the scale is close to $1 / 2$ of that of wind electricity, $1 / 4$ of that of water electricity and 1/10 of that of coal electricity, which have become a very important part of China's power generation industry ${ }^{[5]}$.

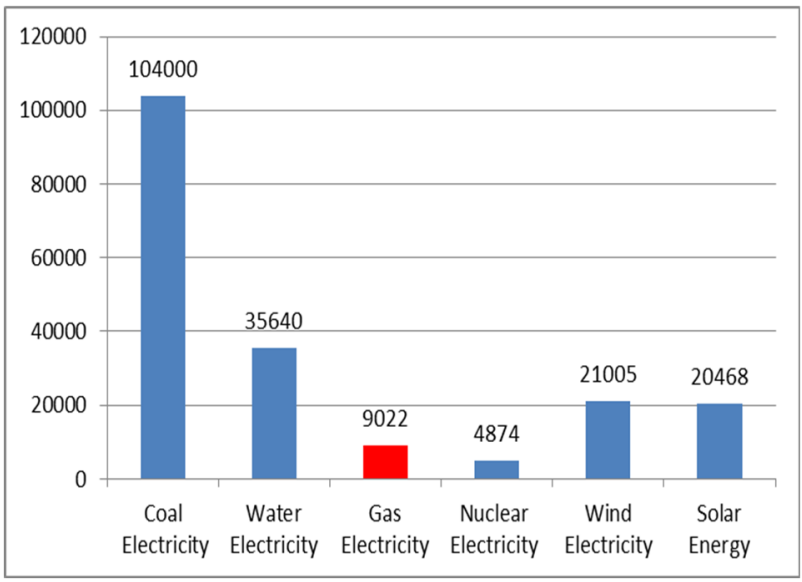

Fig. 1. Installed power supply of all types in 2019 (unit: Million kilowatt hour) .

Due to the economic affordability and construction conditions, China's natural gas power generation capacity is principally concentrated in Guangdong, Jiangsu, Zhejiang, Beijing and Shanghai. Guangdong, Jiangsu and Zhejiang, the big gas and TV provinces, have installed tens of millions of units, while smaller provinces such as Hubei and Xinjiang have fewer than one million units, and some have no natural-gas generators. It can be seen that the distribution of gas turbine units in Different parts of China is still very uneven. The installation of natural gas power generation in key regions of China is shown in Figure 2.

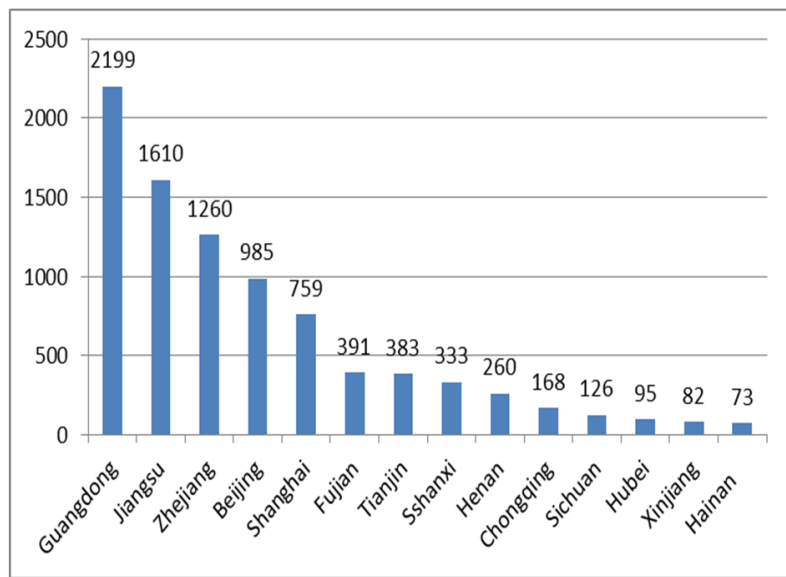

Fig. 2. Installed capacity of natural gas power generation in key regions of China in 2019(unit: 10,000).

\section{Conclusion and Suggestions}

\subsection{Conclusion}

Natural gas power generation has many advantages, especially for ecological and environmental protection can play a positive role. Starting from the essence of eco-city construction, this paper systematically analyzes the energy problems in the process of eco-city construction. Then, by analyzing the principle of natural gas power generation, it is found that natural gas power generation can effectively 
reduce the environmental pollution caused by electric power generation, improve the energy utilization efficiency and reduce the occupation of resources.

Finally, on the basis of the above studies, the following suggestions are made on how to create an appropriate external environment for the development of natural gas power generation:

\subsection{Suggestions}

\subsubsection{Improve the mechanism of electricity price}

Natural gas power generation has many advantages over coal power generation, the most important of which is the environmental protection and flexibility of gas power generation, but the current electricity price policies formulated by all provinces do not fully reflect the environmental protection and peak regulation value of natural gas power generation. Considering the adjustment of national energy structure and increasing the use of natural gas, it is imperative to develop natural gas power generation in the future. Relevant government departments should adjust the policies as soon as possible, improve the on-grid electricity price mechanism, give full consideration to the contributions of gas-fired power generation enterprises in environmental protection and power grid peaking, and mobilize the enthusiasm of natural-gas power generation enterprises and power generation groups in investing in and building natural-gas power plants.

\subsubsection{Increase the protection of air source}

Increase domestic conventional gas, unconventional natural gas, coal gas supply capacity, at the same time increase from Russia, Burma and central Asia and other countries the introduction of natural gas resources, land and through in the coastal stations layout, increase from the Middle East, Asia Pacific, Africa and the Caribbean and other regions of LNG import, realize the air supply, more support.

\subsubsection{Coordinate gas and electricity scheduling}

Establish big data platform, increase joint dispatching of gas network and power grid. In the operation of natural gas power plants, the use of gas should be regulated by the gas supply network, and the power generation should be regulated by the power network. When there is contradiction between power grid dispatch and natural gas quantity, the production and operation of natural gas power plant are extremely passive. It is suggested that the government should take the lead to establish a big data platform to realize timely data sharing and joint dispatching between the gas network and the power grid, so as to ensure the safety, coordination and economy of the operation of the gas network, the power grid and the power generation enterprises.

\subsubsection{Reduce construction cost}

It is an important measure to reduce the cost and operation cost and improve the economy of the project. Try bundling bidding for equipment procurement. Under the coordination of the competent government department, gas turbine of the same grade shall be bundled by bidding, and collectively carry out business and technology negotiation with OEM, so as to expand the content and depth of technology introduction, promote the process of localization of gas turbine, and reduce the equipment purchase price.

\section{References}

1. Xu P, Yang J. Review of China's Energy Industry in 2018 and outlook for 2019 [J]. Petroleum Science and Technology Forum,2019,38(1):8-19.

2. Yuan L. Development and economic analysis of natural gas power generation industry in China [J]. Science and Technology Innovation Herald,2020,17(20):93-95.

3. Wang S, Li Y. Industry policy development and relative suggestion of natural gas distributed energy system in china [J]. Chinese Journal of Environmental Management, 2008,10(3):41-43.

4. Wang S, Wang W. Consideration on the development of natural gas power generation in northeast China- based on the analysis of the distribution of energy and electricity structure in northeast China [J]. Electric Power Technology and Environmental Protection, 2019,35(5):43-46.

5. Wu G. Analysis of market status about natural gas power plant [J]. Zhejiang Electric Power, 2006. 